\title{
Recirculation and Seasonal Change of the Kuroshio From Altimetry Observations
}

\author{
Bo QIU \\ Woods Hole Oceanographic Institution, Woods Hole, Massachusetts
}

\begin{abstract}
Surface height fluctuations across an eastward flowing boundary current, such as the Gulf Stream and the Kuroshio, can be caused by changes both in the upstream inflow and in the neighboring recirculation gyres. Clarifying these causes is important in understanding the timedependent nature of the boundary currents and their relationship to the surface wind and buoyancy forcing. Using satellite altimetry data to identify these causes, however, requires mean surface height field information, which is not readily available from the altimetry observation owing to lack of accurate geoid data. The present study presents a method to estimate the mean surface height profile across a boundary current system (including recirculation gyres) by combining altimetrically measured residual height data and historical hydrographic data. Applying this method to the Kuroshio revealed that the absolute surface height profiles thus estimated agree well with the results from quarterly, in-situ hydrographic observations. By separating the signals of the surface height fluctuations into those of the eastward flowing jet and the recirculation gyres, we found that the seasonal cycle in the surface transport of the Kuroshio, which has a maximum in July and August, is primarily due to the seasonal change in the intensity of the recirculation gyre south of the Kuroshio.
\end{abstract}

\section{INTRODUCTION}

After separating from the western boundaries at Cape Hatteras and Tokara Strait, both the Gulf Stream in the North Atlantic and the Kuroshio in the North Pacific flow into the deep ocean, where they are free from the restraint of continental shelves and are characterized as eastward flowing inertial jets accompanied by large-amplitude meanders and pinched-off eddies. In these deep ocean regions, the Sverdrup constraint on the integrated mass transport of these boundary currents no longer holds. The presence of recirculation gyres to the south and north of the Gulf Stream and the Kuroshio can inflate the volume transports to 3 to 5 times their inflow values upstream in the Florida Strait or along the shelf break of the East China Sea [e.g., Worthington, 1976; Hogg, 1983; Richardson, 1985; Hogg et al., 1986; Masuzawa, 1972; Joyce and Schmitz, 1988].

To characterize and understand low-frequency, large-scale fluctuations of these eastward flowing jets has been the subject of many studies in the past. In particular, satellite altimetry observations with their global coverage and temporal repetition provide a new means for monitoring these fluctuations. For example, Fu et al. [1987] studied the seasonal variability of the Gulf Stream based on the GOES3 altimetry data and found a springtime intensification in the eastward surface transport. Seasonal variability of the Gulf Stream transport was also studied by Tai [1990], Kelly [1991], and Zlotnicki [1991] based on the altimetry data from the Geosat Exact Repeat Mission (ERM, 17 day repeat cycle). Although the analysis methods differed, these Gulf Stream studies showed a tendency for larger surface transports to appear in the fall. The fall-maximum tendency was also found in the surface transport of the Kuroshio Extension during the Geosat ERM period [Tai, 1990; Zlotnicki, 1991; Qiu et al., 1991].

\section{Copyright 1992 by the American Geophysical Union.}

Paper number 92JC01792.

0148-0227/92/92JC-01792\$05.00
In addition to the seasonal variability, studies by Kelly [1991] and Qiu et al. [1991] have further investigated the relationship between the current path and the surface transport based on a simple model of a meandering jet [Kelly and Gille, 1990]. In the 2.5-year period of the Geosat ERM (November 1986 to April 1989), they found that the large-scale fluctuations in the surface transport were significantly correlated with the current path fluctuations, with more northerly path positions coinciding with larger surface transport values for both the Gulf Stream and the Kuroshio Extension. Though similar in the correlation between the transport and the path position, the large-scale fluctuations in the Gulf Stream and the Kuroshio Extension had different frequencies: the Gulf Stream fluctuated primarily on time scales of months, whereas the Kuroshio Extension exhibited a trend over the 2.5 years. The interannual fluctuations in the Kuroshio Extension were speculated to be related to the 1986-1987 El Niño-Southern Oscillation (ENSO) event in the low-latitude Pacific Ocean.

The surface transport fluctuations found in the aforementioned studies are the sum of the changes in the net eastward flow through the upstream western boundary plus those in the recirculation gyres north and south of the Gulf Stream and the Kuroshio. In order to identify the causes for the large-scale, low-frequency fluctuations and to further understand the relationship between the transport and position of a boundary jet, it is necessary to separate the fluctuations of the net flow from those of the recirculation gyres. So far, because of their vast geographical extent, little is known about the low-frequency changes in the recirculation gyres. Although changes in the transport of the upstream Gulf Stream and Kuroshio have been investigated using hydrography and tidal gauge data [e.g., Niiler and Richardson, 1983; Schott and Zantopp, 1985; Blaha and Reed, 1982; Kawabe, 1988], a recent study by Greatbatch and $L i$ [1990] showed that the phase change in the eastward jet caused by periodic Sverdrup transport fluctuations can be a complicated function of downstream location due to the presence of the mean ocean circulation. This indicates that the fluc- 


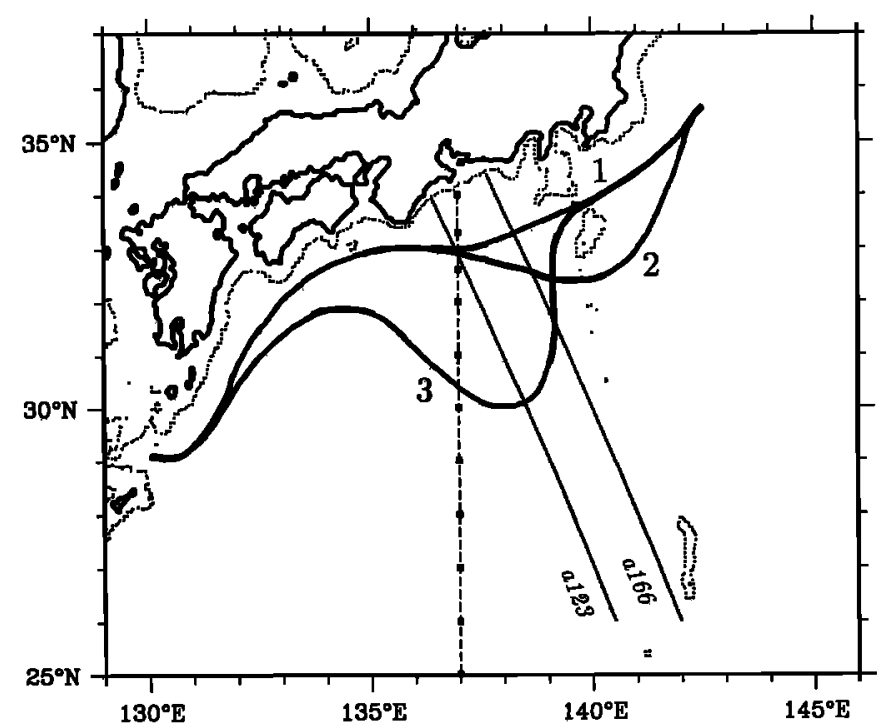

Fig. 1. Typical paths of the Kuroshio south of Japan: (1) nearshore non-large-meander path, (2) offshore non-largemeander path, and (3) large-meander path [Kawabe, 1985]. In the figure, diagonal lines denote the Geosat ascending subtracks, a dashed line denotes the Japan Meteorological Agency (JMA) $137^{\circ} \mathrm{E}$ repest hydrographic section, and dotted lines denote the 500-m isobaths.

tuations observed in the Florida. Strait or the East China Sea may not be easily extrapolated to account for the net eastward flow changes in the downstream extension regions.

With the ongoing satellite mission of ERS-1 and the forthcoming mission of TOPEX/Poseidon, more altimetric data will be available to us in the next decade. In the present study, I address the question of whether, and to what extent, we can separate the signals due to the net eastward flow from those due to the recirculation gyres using altimetry observations. In the next section, I briefly review the altimetry observations and show that separating the signals requires the mean surface height profile along a satellite subtrack. In section 3, I present a method to estimate the mean surface height profile including recirculation gyres by extending the synthetic method of Kelly and Gille [1990]. This method is applied to two ascending subtracks in the Kuroshio region south of Japan (Figure 1), where regular hydrographic surveys during the Geosat ERM period make it possible to check the reliability of the proposed method (section 4). Finally, I show that the results of the separated signals are useful in determining the cause of the low-frequency fluctuations of the Kuroshio.

Note that the recirculation gyre south of the Kuroshio has been conventionally known as the Kuroshio Countercurrent and the recirculation gyre north of the Kuroshio, the Cold Water Mass [e.g., Taft, 1972]. For simplicity, however, I will refer to them as the southern and northern recirculations of the Kuroshio.

\section{Residual Height Changes vs. Recirculation Changes}

Satellite-borne radar altimeters measure the distance between the satellite and the sea surface. Combined with the satellite position and the Earth's gravity field (the geoid) information, this measurement can be used to determine the sea surface height field and to infer the surface geostrophic velocity field [e.g., Wunsch and Gaposchkin, 1980]. Unfortunately, the geoid is not known on length scales of a few hundred kilometers. Lack of accurate geoid information limits the altimetry measurements to providing only the residual components of the sea surface height (i.e., the surface height deviations from the temporal mean).

In the Gulf Stream or the Kuroshio region, where the eastward flowing jet makes large lateral excursions compared to its width, typical residual height profiles, $h^{\prime}(y, t)$, measured by the Geosat altimeter are like those shown in Figure 2. Owing to the large lateral excursions of the jet, the mean surface height profile has a more gradual slope than the instantaneous height profiles, leaving informative signals of the jet in the residual height profiles. Figure $3 a$ shows the height profiles when an idealized eastward flowing Gaussian jet migrating laterally. The distinction in the height slope between the mean and the instantaneous height profiles (right panel) enables us to estimate, as a good initial guess, the center position of the jet (at the maximum - $\partial h^{\prime} / \partial y$ point, where $y$ is the northward along-track distance) and the jet width (the negative $\partial h^{\prime} / \partial y$ region surrounding the jet center) from the residual height data (left panel; also see Kelly and Gille [1990]).

To the south of the jet, Figure 2 shows the existence of

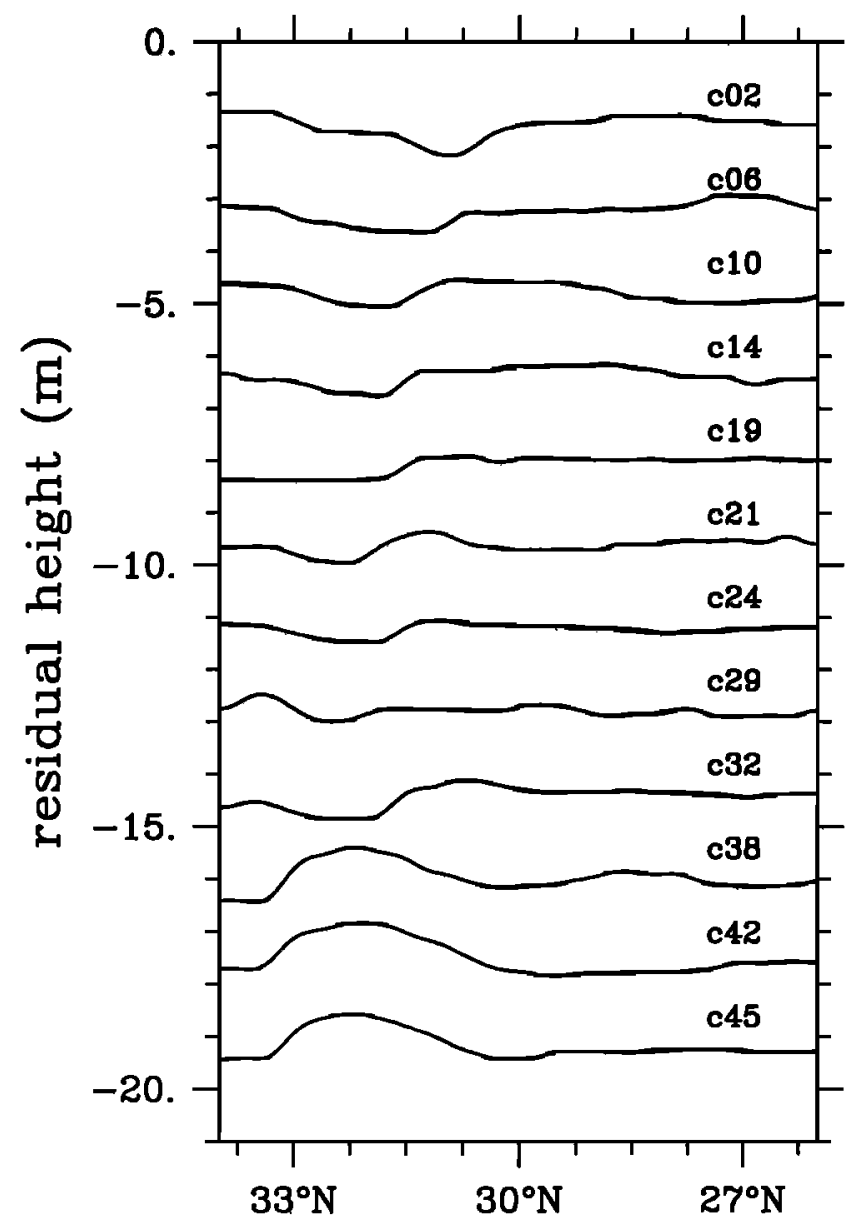

Fig. 2. Typical residual height profiles $h^{\prime}(y, t)$ along subtrack a123 after correction for various effects of the atmosphere, removal of the orbital error, and low-pase filtering (see Qiv et al. [1991] for a detailed description on the processing of the data). Each height profile in the panel is shown with an offiet of $2.0 \mathrm{~m}$, and the number next to it denotes the repeat cycle of the Geosat ERM. 

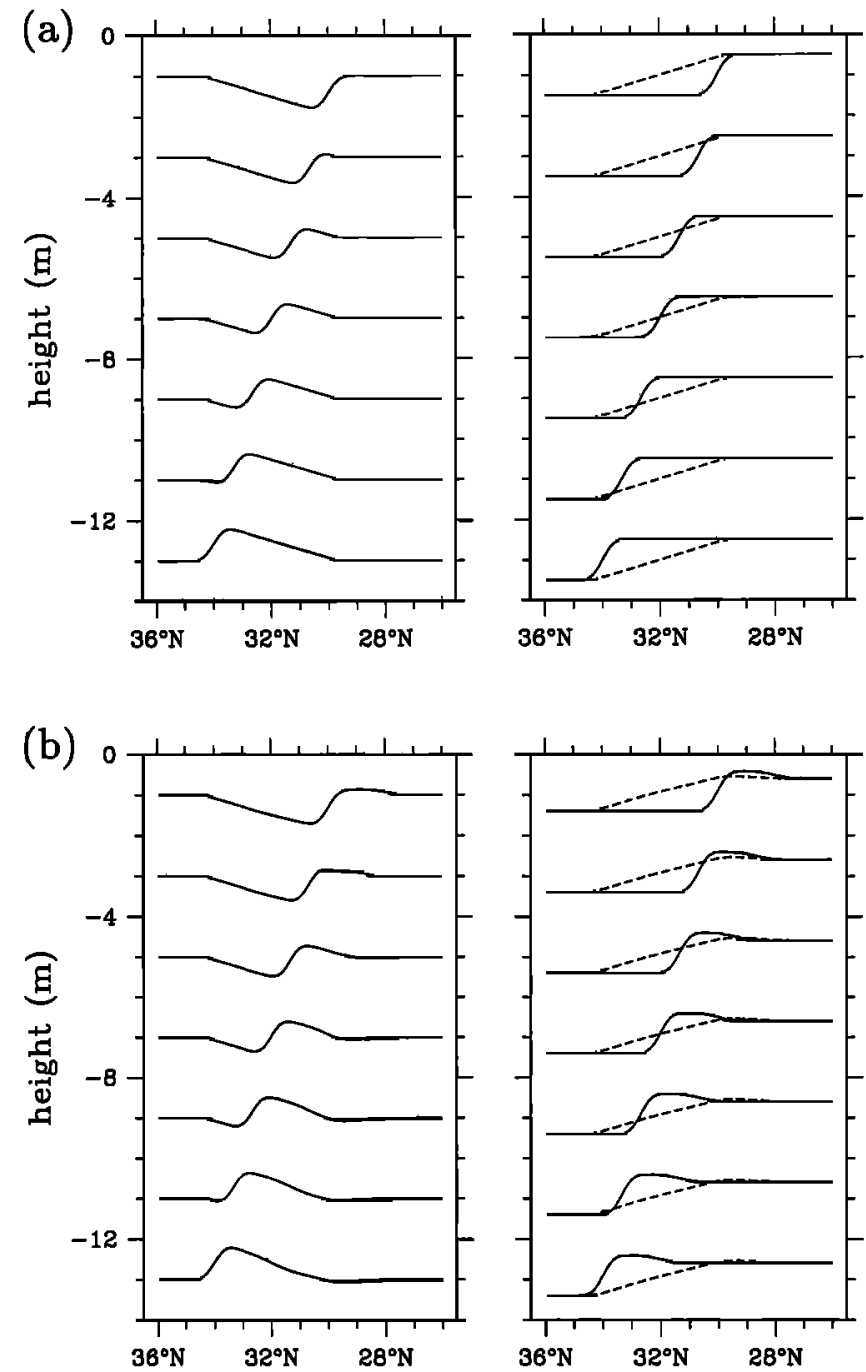

Fig. 3. (a) Profiles of (left) residual surface height and (right) instantaneous surface height (solid lines) of a Gaussian-shaped eastward flowing jet migrating laterally. Dashed lines denote the mean surface height profile from averaging the instantaneous height profiles. (b) Same as in Figure $3 a$ except for the existence of a southern recirculating flow that comigrates with the eastward flowing jet. The recirculating flow has an amplitude $20 \%$ that of the eastward jet and a width twice that of the eastward jet. The two jets are separated by $2^{\circ}$.

a westward residual velocity region with $\partial h^{\prime} / \partial y>0$. Do these signals represent fluctuations in the southern recirculation gyre? To answer this question, I show in Figure $3 b$ the synthetic height profiles when a southern recirculating flow comigrates north and southward with the main eastward jet. Comparing the residual height data in the left panel with those of Figure $3 a$, we notice that the height patterns in the $\partial h^{\prime} / \partial y>0$ region are similar, despite the fact that the changes in profile shape in Figure $3 a$ are solely due to the meandering of the jet. Because the recirculation gyres always border the eastward jet, these results indicate that if only the residual height data are available, there is ambiguity in separating the height fluctuations due to the recirculation gyres from those due to the jet meandering. To remove such ambiguity, we need to have some knowledge of the mean surface height profiles along the satellite subtracks.

\section{Estimating Mean Surface Height Profiles With ReCIRCULATION}

Using the distinct slope characteristics between the mean surface height profile and the instantaneous surface height profiles (Figure 3a), Kelly and Gille [1990] developed a simple jet model to estimate the mean surface height profile based on the residual height data along a satellite subtrack. In this method, the instantaneous velocity profile of the eastward jet is assumed to be a Gaussian function of the form

$$
u_{s}(y, t)=a_{1} \exp \left[\frac{-\left(y-a_{2}\right)^{2}}{2 a_{3}{ }^{2}}\right],
$$

where $a_{1}(t)$ is the velocity maximum, $a_{2}(t)$ is the center position of the jet, and $a_{3}(t)$ is the width parameter. The assumption that the cross-stream velocity profile of the Gulf Stream is close to Gaussian-shaped is supported by both acoustic Doppler current profiler (ADCP) and subsurface mooring observations [e.g. Hall and Bryden, 1985; Joyce et al., 1986]. The surface height profile associated with the Gaussian jet is

$$
h_{s}(y, t)=-\frac{f}{g} a_{1} a_{3} \sqrt{\pi / 2} \operatorname{erf}\left(\frac{y-a_{2}}{\sqrt{2} a_{3}}\right),
$$

where $\operatorname{erf}(y)$ is the error function. For each cycle, $a_{i}$ are initially estimated from the residual height profiles and the synthetic height profile is calculated according to (2). The temporal average of the synthetic height profiles then gives a synthetic mean height profile $\left\langle h_{0}\right\rangle(y)$. Estimates of $a_{i}$ are improved by an iterative fit of the synthetic height data to the residual height data plus the synthetic mean. The iteration is performed until $\left\langle h_{s}\right\rangle(y)$ converges.

Notice that the detailed velocity pattern of an instantaneous boundary current (either the Gulf Stream or the Kuroshio) may deviate from the Gaussian shape owing to unstable waves, eddies and other physical processes near the boundary current. The Gaussian profile is assumed only for the purpose of estimating the mean surface height profile along a satellite subtrack; it provides the gross structure of the instantaneous boundary current, namely, its position, width, and maximun speed. This information about the instantaneous boundary current is adequate for estimating the mean surface height profile over a period of years, because contributions from the unstable waves and eddies to the mean field should be small. Once the mean surface velocity profile is estimated, the instantaneous surface velocity is calculated from the sum of the mean and the residual height. Since the unstable wave and eddy information is basically included in the residual height data, the resultant instantaneous surface velocity profiles retain the non-Gaussian characteristics of the instantaneous boundary current.

Applying this synthetic model to the Geosat subtrack from Bermuda to Cape Cod, Kelly et al. [1991] and Joyce et al. [1990] have shown that the surface height profiles derived from the altimetry data agreed with those from the nearly simultaneous hydrographic and ADCP data within the estimated errors in the measurements, that is, rms differences of $0.05 \mathrm{~m}$. More recently, Qiu et al. [1991] have extended the method to estimate the two-dimensional mean surface height field by combining ascending and descending subtrack data. The mean surface height field thus estimated for the Kuroshio Extension region is found to be in good 


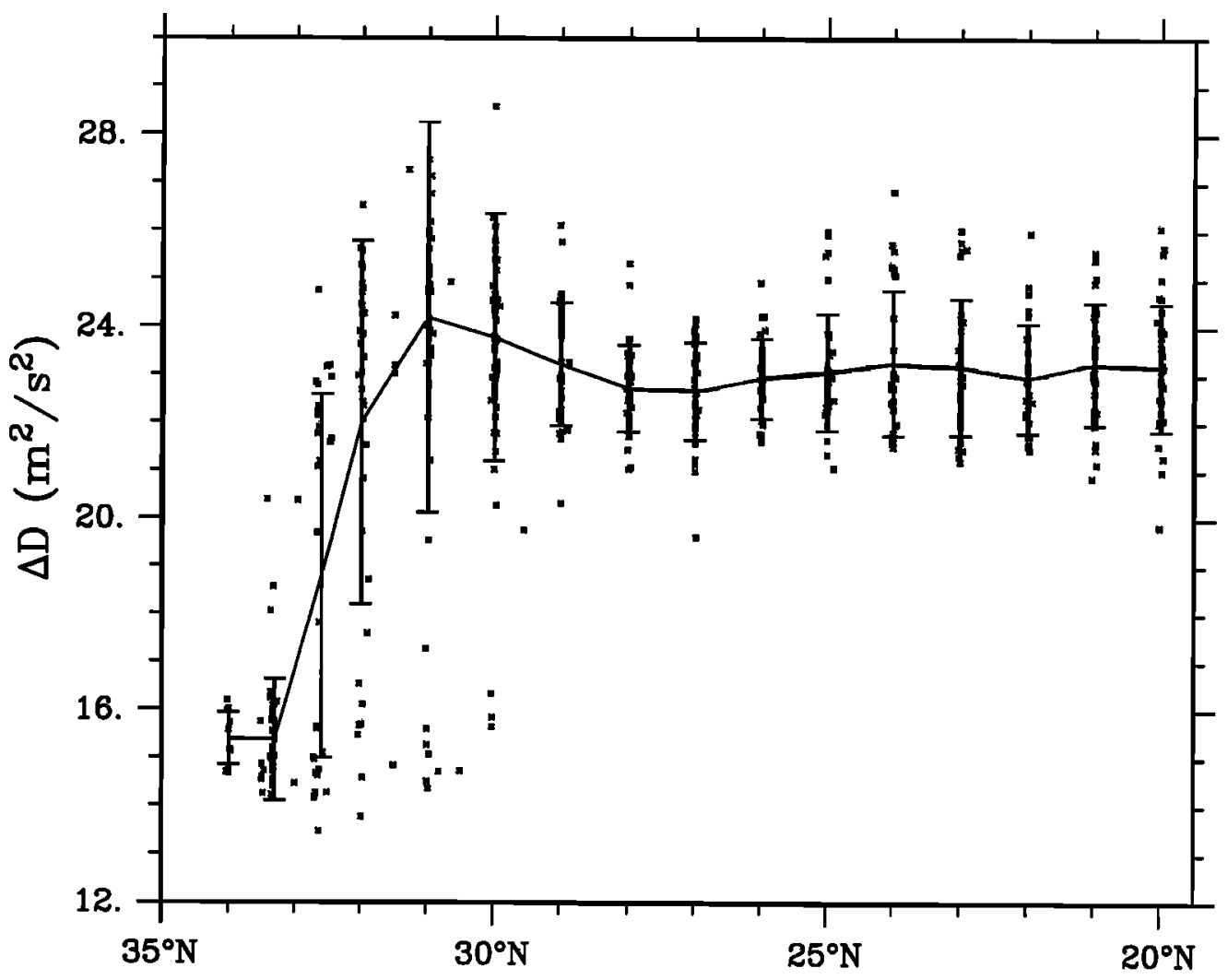

Fig. 4. Sea surface dynamic height values $(0 / 1200 \mathrm{dbar})$ along the $137^{\circ} \mathrm{E}$ meridian based on the semiannual hydrographic surveys by JMA from 1967 to 1988 . The solid line is the mean height profile with vertical bars indicating the standard deviations.

agreement with the mean dynamic height field calculated from long-term hydrographic data.

An apparent drawback of the synthetic model is that it assumes the height jump associated with the eastward jet remains unchanged away from the current. As was discussed in the introduction, the actual flow field adjacent to the Kuroshio or the Gulf Stream includes recirculation gyres whose existence can modify the mean surface height field away from the jet. Figure 4 shows the surface dynamic height profile averaged from repeated hydrographic surveys along $137^{\circ} \mathrm{E}$ by the Japan Meteorological Agency (see Figure 1 for the location). Apart from the sharp surface height drop corresponding to the mean eastward flow of the Kuroshio, a gradual surface height drop south of $31^{\circ} \mathrm{N}$ corresponds to the mean westward flow of the southern recirculation gyre. To accurately estimate recirculation fluctuations, we need to modify the synthetic model and determine the mean surface height profile including recirculation gyres.

It is worth mentioning that the convergence of the synthetic method requires that the ratio $\sigma\left(a_{2}\right) /\left\langle a_{3}\right\rangle$ be large, where $\sigma\left(a_{2}\right)$ is the standard deviation of the jet position changes and $\left\langle a_{3}\right\rangle$ is the mean jet width (Figure 5 ). The recirculation gyres' relatively large width scales and their relative stability in space precludes us from modeling the westward recirculating flows by simply adding westward jets and repeating the iterative procedures. To estimate the mean height field including recirculation gyres, I adopt a different approach, that is, to use the mean surface height profile estimated for the eastward flowing jet, $\left\langle h_{s}\right\rangle(y)$, as a base and to modify this profile to include possible recirculation gyres. I represent the instantaneous cross-track velocity profile by

$$
\begin{array}{r}
u_{r}(y, t)=a_{1} \exp \left[\frac{-\left(y-a_{2}\right)^{2}}{2 a_{3}^{2}}\right]-b_{1} \exp \left[\frac{-\left(y-b_{2}\right)^{2}}{2 b_{3}^{2}}\right] \\
-c_{1} \exp \left[\frac{-\left(y-c_{2}\right)^{2}}{2 b_{3}{ }^{2}}\right]
\end{array}
$$

where $a_{i}(t)$ are the parameters for the eastward jet determined from the single jet model (1), and $b_{i}(t)$ and $c_{i}(t)$ are the parameters for the recirculating westward flows south and north of the eastward jet. To determine $b_{i}(t)$ and $c_{i}(t)$, I first calculate the time series of $h^{\prime}(y, t)+<h_{0}>(y)$. For each cycle, initial guesses for $b_{2}$ and $c_{2}$ (centers of recirculation gyres) are chosen at locations with maximum $\partial\left[h^{\prime}+<h_{\bullet}>\right] / \partial y$ values south and north of the eastward jet. When maxima of $\partial\left[h^{\prime}+<h_{s}>\right] / \partial y$ are not available, either because the mean westward flows are not included at this stage or because of the actual weakening of the recirculation gyres, $b_{2}$ and $c_{2}$ are set to be $a_{2}-2^{\circ}$ and $a_{2}+1^{\circ}$, respectively. Initial guesses for the widths of the recirculating flows are $b_{3}=2 a_{3}$ and $c_{3}=a_{3}$, based on previous studies of oceanographic conditions south of Japan [ $\mathrm{Uda}$ and $\mathrm{Ha}$ sunuma, 1969; Taft, 1972]. For initial $b_{1}$ and $c_{1}$, I assume that they are proportional (by a factor of $\beta$ ) to the height jump across the residual recirculating westward flows. The synthetic height profile including recirculation is now

$$
\begin{aligned}
h_{r}(y, t)= & h_{s}(y, t)+\beta \frac{f}{g} \sqrt{\pi / 2} \times \\
& {\left[b_{1} b_{3} \operatorname{erf}\left(\frac{y-b_{2}}{\sqrt{2} b_{3}}\right)+c_{1} c_{3} \operatorname{erf}\left(\frac{y-c_{2}}{\sqrt{2} c_{3}}\right)\right] . }
\end{aligned}
$$




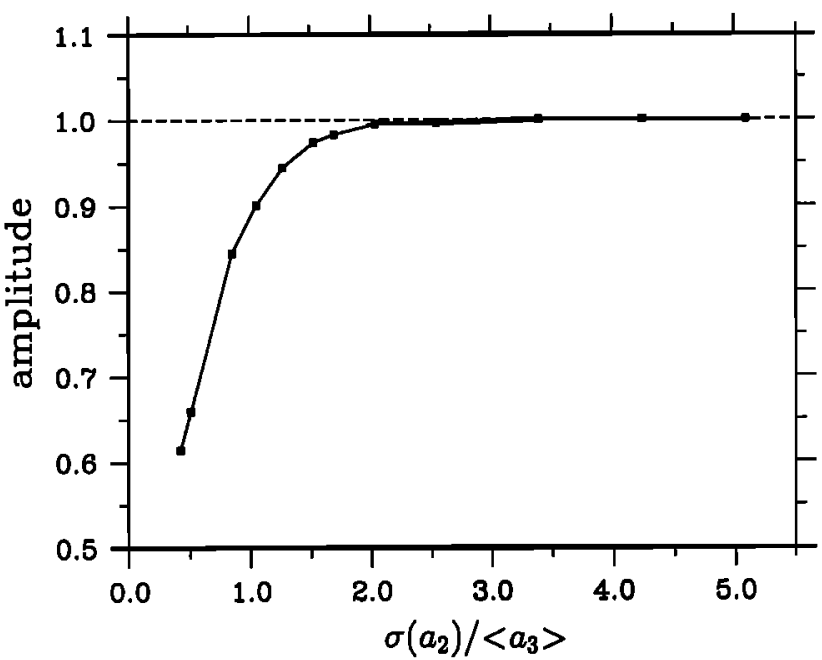

Fig. 5. Fraction of original amplitude recovered in synthetic mean. Because the method of Kelly and Gille depends on the meandering of a jet to recover the mean sea surface height profile, it underestimates the mean height difference when the meandering falls below a critical level. Using a simple model assuming that the jet fluctuates laterally, an estimate of the fraction of the original amplitude was computed as a function of the amount of meandering, as measured by the ratio of the standard deviation of position, $\sigma\left(a_{2}\right)$, to the mean width parameter, $a_{3}$.

The estimates of $b_{i}$ and $c_{i}$ are improved by least squares fits of the individual synthetic height profile (4) to the residual height data plus the synthetic mean height to minimize

$$
\sum_{y}\left[h^{\prime}(y, t)+<h_{r}>(y)+\gamma-h_{r}(y, t)\right]^{2},
$$

where $\gamma(t)$ is a constant offset to account for uncorrected orbit errors. For the subtracks across the Kuroshio, the sum over $y$ is taken from $26^{\circ} \mathrm{N}$ to the Japanese coast and the nonlinear parameter fitting in (5) is performed using the Levenberg-Marquardt method [Press et al., 1986]. After improving $b_{i}(t)$ and $c_{i}(t)$, I calculate the time series of $h^{\prime}(y, t)+<h_{r}>(y)$ and repeat the procedures described above once again. This repetition helps us in choosing better initial values of $b_{i}$ and $c_{i}$ because the synthetic mean profile $\left\langle h_{r}\right\rangle$ (instead of $\left\langle h_{0}\right\rangle$ ) now contains the first guess of the mean recirculation. To determine the amplitude factor $\beta$ in (4), I assume that the mean surface height difference across the entire boundary current system, $\langle\delta h\rangle$, is known a priori. The value of $\beta$ is chosen such that the surface height difference in the resultant $\left\langle h_{r}\right\rangle(y)$ is equal to this a priori $\langle\delta h\rangle$ value.

To test this approach, I applied it to the two subtracks across the Kuroshio (Figure 1). The dashed lines in Figure 6 show the $\left\langle h_{s}\right\rangle(y)$ profiles using the single-jet model of Kelly and Gille [1990]. To modify these mean height profiles using the aforementioned procedures, I specified the $\langle\delta h\rangle$ value from the climatological surface dynamic height data of Figure 4, namely, $\langle\delta h\rangle=0.76 \mathrm{~m}$ across the Kuroshio system of $26^{\circ}-34^{\circ} \mathrm{N}$ (see appendix for the discussion of choosing $\langle\delta h\rangle$ values). The resultant $\left\langle h_{r}\right\rangle(y)$ profiles are shown in Figure 6 by solid lines. Comparing these profiles with Figure 4 shows that the surface height differences across the mean eastward jet are both about $0.9 \mathrm{~m}$ and the surface height differences across the southern recirculation about $0.12 \mathrm{~m}$. Both results reveal that the northern recirculation is very

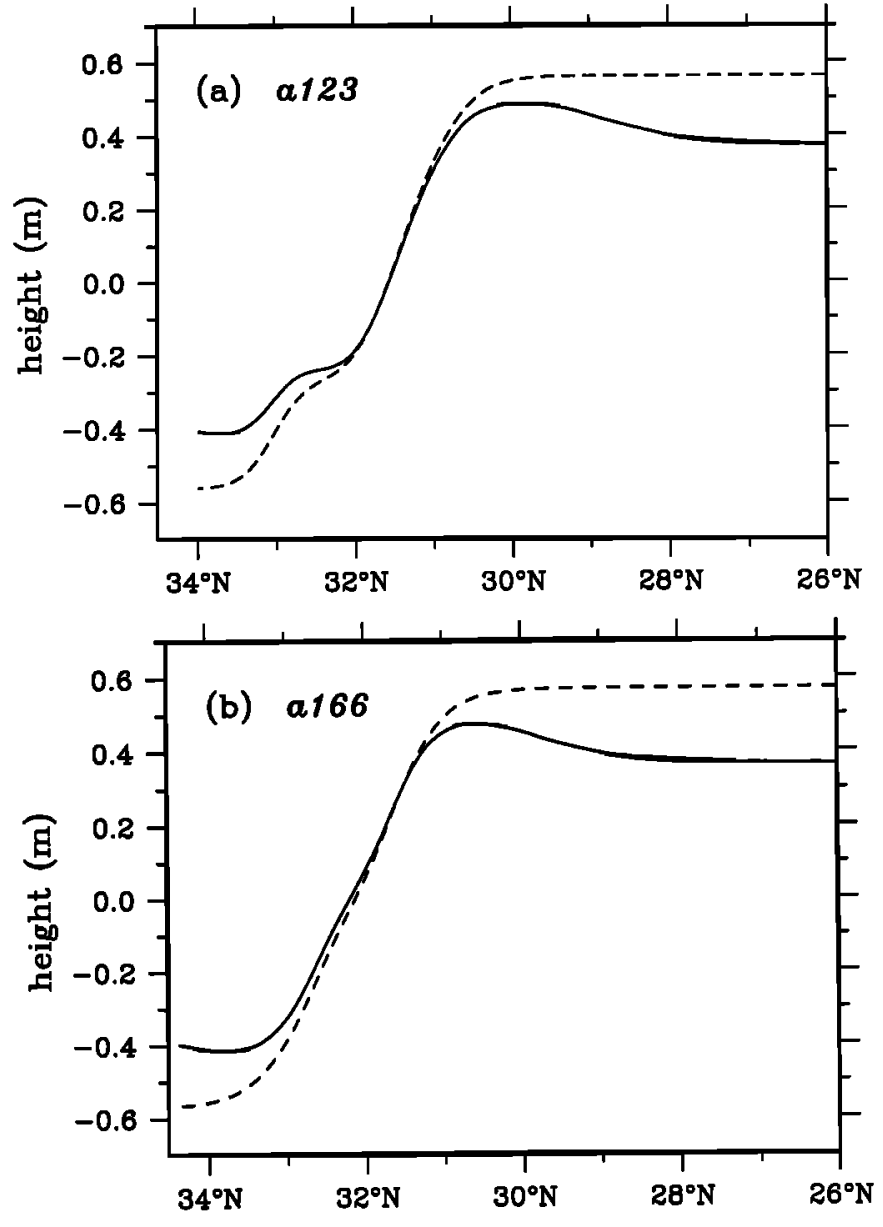

Fig. 6. Estimated mean surface height profiles along subtracks (a) a123 and (b) a166. Dashed lines show the profiles of $\left\langle h_{a}\right\rangle(y)$ when a single eastward flowing jet is assumed in the instantaneous velocity field. Solid lines denote the profiles of $\left\langle h_{r}\right\rangle(y)$, which assumes the existence of westward recirculating flows in the velocity field. In calculating $\left\langle h_{r}\right\rangle(y)$, the mean surface height jump across the Kuroshio system (from $26^{\circ} \mathrm{N}$ to the Japanese coast) is set at $0.76 \mathrm{~m}$.

weak in the mean height field. Along the subtrack a123 (Figure $6 a$ ), we notice that in addition to a sharp height increase around $31.5^{\circ} \mathrm{N}$, a small secondary height jump exists around $33^{\circ} \mathrm{N}$. This double jump structure in the mean height profile is due to the distinctive path selection of the Kuroshio, being either in a meander path state or in a nearshore path state, along this subtrack (see Figure 1 and next section). The double jump structure is not clear in Figure 4, possibly as a result of the coarse resolution of the hydrographic surveys and to the fact that the height profile in Figures 4 is averaged over a different time period. In a downstream region along subtrack a166 (Figure $6 b$ ), the mean height profile has a smoother height increase due to the smoother path variations of the Kuroshio there.

\section{VARIABILITY OF THE KUROSHIO AND THE Recirculation GYres: A COMPARISON With Hydrographic SuRveys}

Once the mean surface height profiles are estimated, we can obtain the time series of the instantaneous height profiles by simply adding the mean $\left\langle h_{r}\right\rangle(y)$ to the residual data $h^{\prime}(y, t)$. Figure 7 shows examples of the instantaneous 


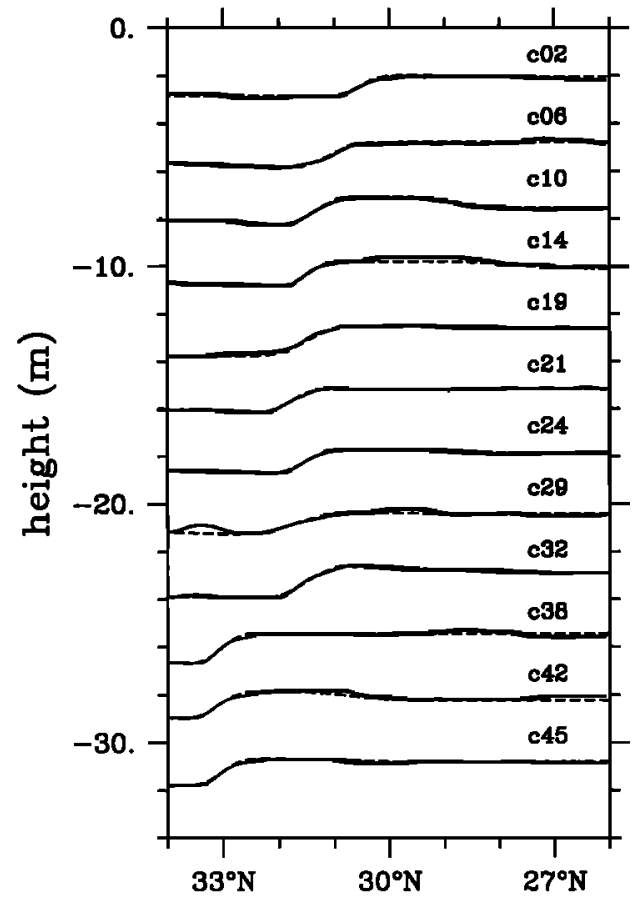

Fig. 7. Synthetic height profiles $h_{r}(y, t)$ (dashed lines) versus the profiles of the sum of the residual height and the synthetic mean height $h^{\prime}(y, t)+\left\langle h_{r}\right\rangle(y)$ (solid lines) along subtrack a123.

height profiles along subtrack a123 (solid lines) after adding the synthetic mean profile to the residual height data (see Figure 2). Dashed lines denote the synthetic height profiles $h_{r}(y, t)$, defined by (4), that best fit the solid lines. The good agreement between the solid and dashed lines in Figure 7 confirms that it is appropriate to represent the instantaneous velocity profile of the Kuroshio and its recirculation by a triple-Gaussian function. Figure 8 shows the time series of the center location of the Kuroshio $\left(a_{2}\right)$ and the surface height differences across the eastward flowing Kuroshio $\left(\delta h_{\text {east }}\right)$, the northern recirculating flow $\left(\delta h_{\text {north }}\right)$, the southern recirculating flow ( $\delta h_{\text {south }}$ ), and the entire Kuroshio flow from $26^{\circ} \mathrm{N}$ to the coast $\left(\delta h_{\text {net }}\right)$ based on the instantaneous height profiles. Before discussing the time-dependent features of these quantities, it is helpful to compare the results with the available data from hydrographic surveys.

During the Geosat ERM period, sea conditions south of Japan were extensively observed by hydrographic surveys through the "Japan-China Joint Research Program on the Kuroshio." Figure 9 shows the seasonal averages of the surface dynamic height field (0/1000 dbar) based on publications of Japan Oceanographic Data Center (JODC). During the first two seasons of the Geosat ERM (fall 1986 and winter 1987), Figure 9 shows that the Kuroshio changed from a typical straight path to a large meander path. The path remained in the large meander state for 1.5 years and thereafter evolved into a typical offshore non-large-meander path state in summer of 1988 (see Figure 1 for nomenclature). This path change of the Kuroshio, from a straight state to a meander state and to an offshore non-large-meander state, can be easily identified in the time series of Figure $8 \mathrm{a}$. Notice that the transition from the straight path to the large meander path, according to Figure $8 a$, occurred in a time scale shorter than 17 days.

To compare the time series of the surface height differ- (a)

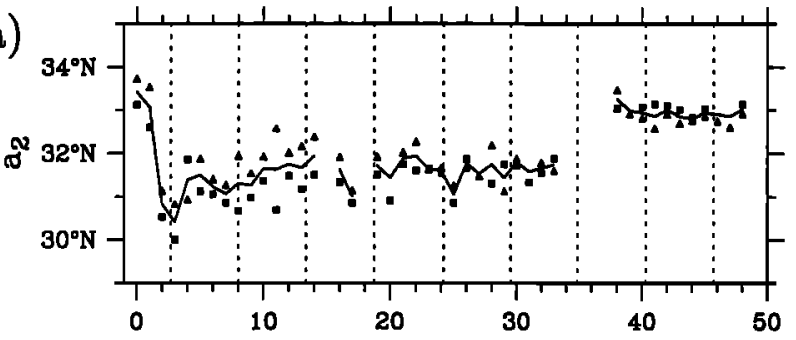

(b)
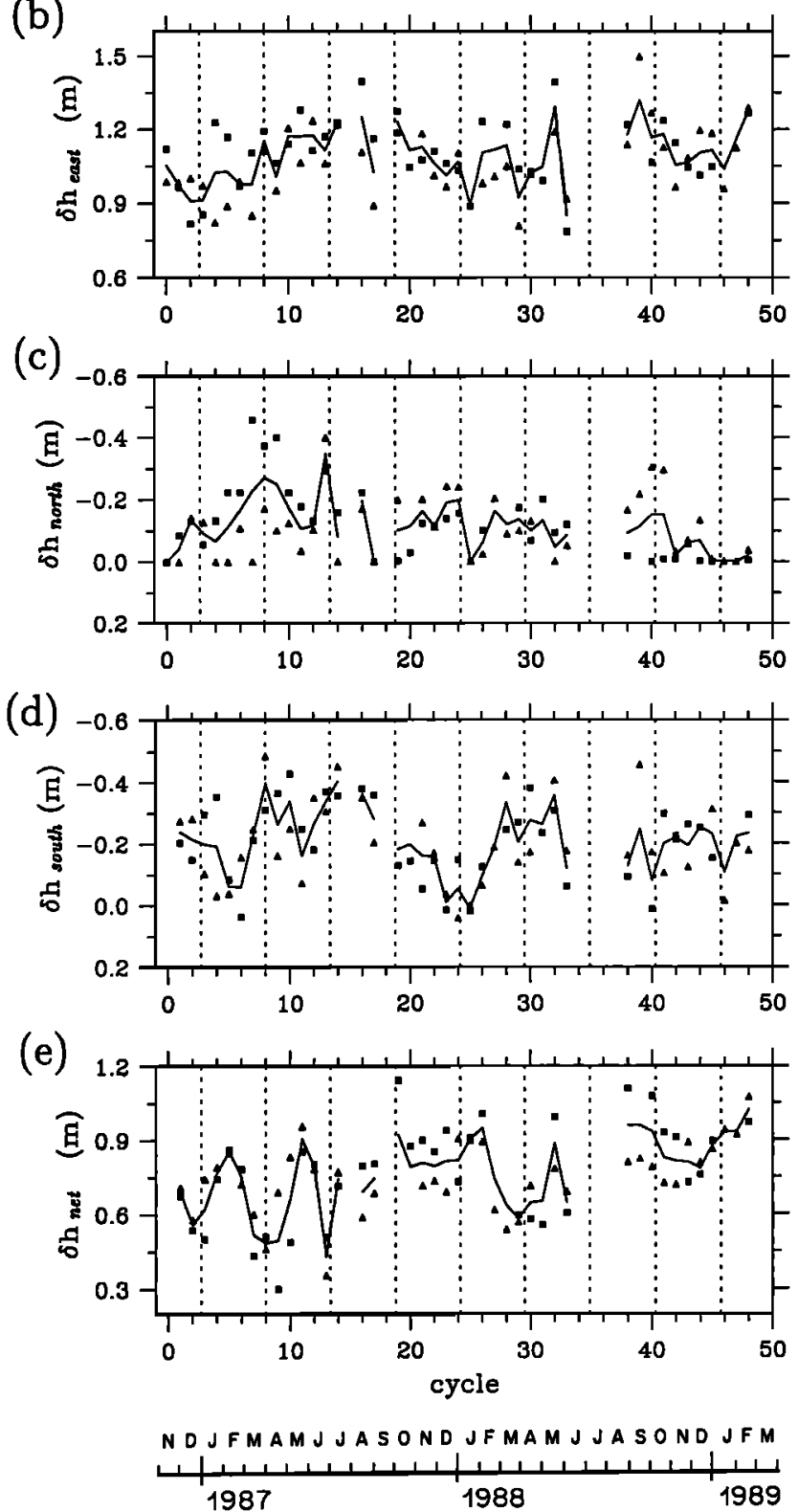

Fig. 8. Time series of (a) the center location of the Kuroshio, $(b)$ the surface height difference $(\delta h)$ across the eastward flowing Kuroshio, (c) $\delta h$ across the northern recirculating flow, (d) $\delta h$ across the southern recirculating flow, and (e) $\delta h$ across the entire Kuroshio aystem from $26^{\circ} \mathrm{N}$ to the coast. In each panel, squarea denote values from subtrack $\mathbf{8 1 2 3}$ and triangles denote date from subtrack a166. Solid lines are the average of the two subtracks.

ences determined from the altimetry observations with the seasonal mean values from the hydrographic surveys, I first binned the $\delta h$ data in Figure 8 into 10 seasons (comparisons are done only for the data along subtrack a123 because the 

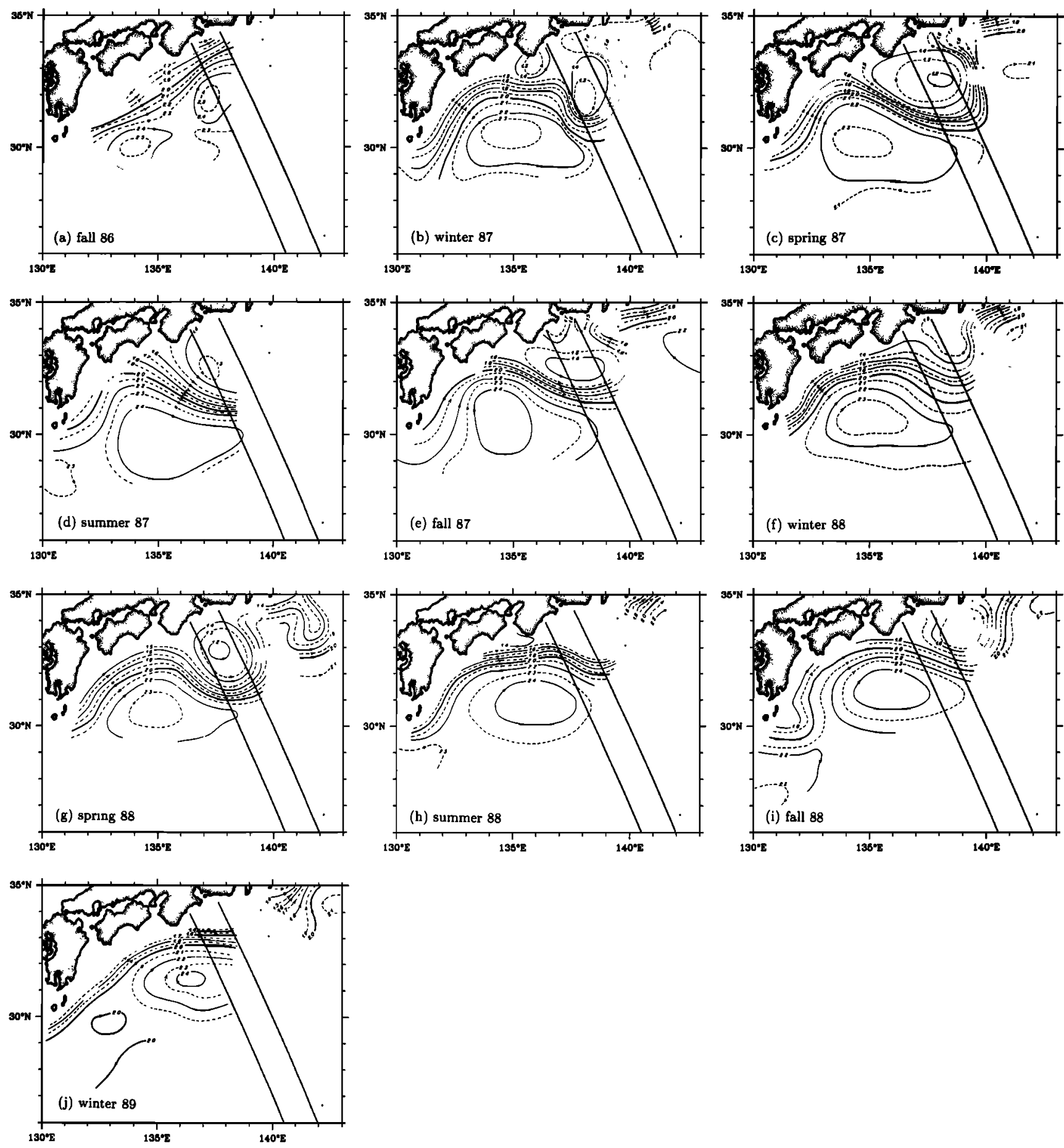

Fig. 9. Quarterly-averaged surface dynamic height field (0/1000 dbar) from hydrographic surveys (JODC [19871990]): (a) fall 1986, (b) winter 1987, (c) spring 1987, (d) summer 1987, (e) fall 1987, ( $f$ ) winter 1988, (g) spring 1988, $(h)$ summer 1988, (i) fall 1988, $(j)$ winter 1989. Here, winter is defined as January, February, and March. Contours are in units of $10 \mathrm{~m}^{2} \mathrm{~s}^{-1}$. Superimposed diagonal lines denote the Geosat subtracks.

hydrographic surveys are more complete there). For each season, I calculated the mean and the fluctuation range of $\delta h$ based on all available data points with the exception of fall of 1986 when the Kuroshio changed abruptly from the straight path to the large meander path. Since the $\Delta D$ map in Figure $9 a$ is based entirely on hydrographic surveys before December 1986, when the Kuroshio was in a straight path, only the first two cycle data of the Geosat were used to represent that season. Figure $10 a$ shows the seasonally averaged $\delta h_{\text {east }}$ values and their fluctuation ranges (solid marks and bars). Open marks in the figure denote the surface height differences across the eastward flowing Kuroshio based on maps of Figure 9. Vertical bars denote a $0.1 \mathrm{~m}$ interval which is the resolution of the height contours in Figure 9. Notice that the time series of the open marks in Figure $10 \mathrm{a}$ has been offset by an arbitrary constant of $0.15 \mathrm{~m}$ for 
a better comparison. Since the Kuroshio reaches a depth deeper than $1000 \mathrm{~m}$ [e.g., Ishii et al., 1983], this offset value accounts for the discrepancy between the $\delta h$ value from the hydrography (which is referred to the $1000-\mathrm{m}$ depth) and the absolute surface height difference from the altimetry observation. Apart from the constant offset, the agreement between the two time series in Figure $10 a$ is generally good, with the independently measured $\delta h_{\text {east }}$ values falling within the fluctuation ranges of the two measurements. The largest disagreement occured in fall of 1988 , wherein $\delta h_{\text {east }}$ from the hydrographic surveys is about $0.25 \mathrm{~m}$ smaller than that from the altimetry observations. The reason for this discrepancy is unclear, though it seems not to be due to the undersampling of the altimetry data.

A similar comparison is shown in Figure $10 b$ for the surface height difference across the northern recirculating flow, $\delta h_{\text {north }}$. As in Figure $10 a$, the two independently measured time series again agree well with each other. Notice that
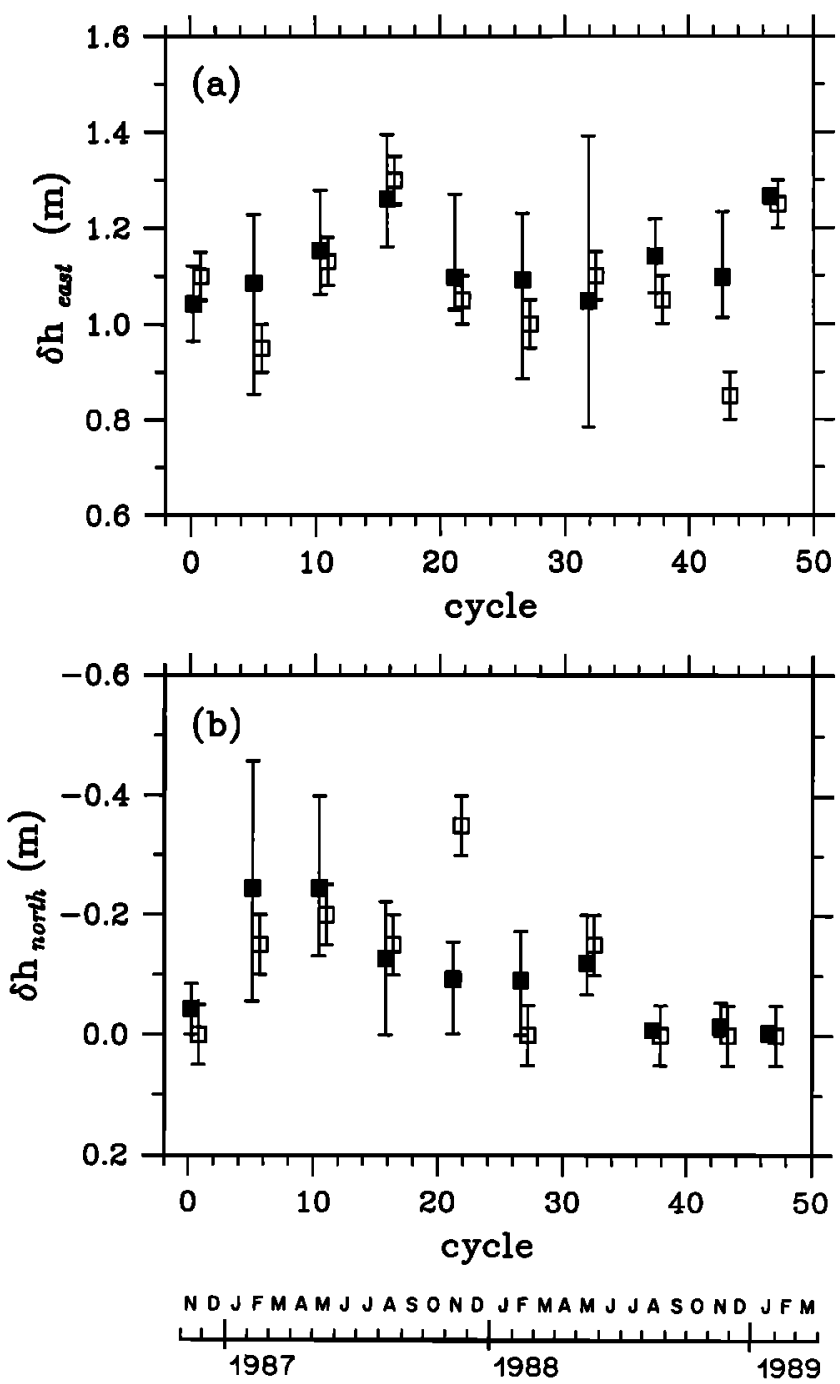

Fig. 10. Seasonal averages of the surface height difference across (a) the eastward flowing Kuroshio and $(b)$ the northern recirculating flow along the subtrack a123. Solid marks are from the altimetry observations (Figure 8) with vertical bars denoting the fluctuating ranges. Open marks are values based on hydrographic surveys and vertical bars indicate a $0.1-\mathrm{m}$ interval, the resolution of height contours in Figure 9. In Figure 10a, the time series of the hydrographic data is shown with an offet of $0.15 \mathrm{~m}$. no offset is added to the $\delta h_{\text {north }}$ values shown in Figure $10 b$, suggesting that the influence of the northern recirculation gyre is possibly limited to the upper 1000-m layer. In fall 1987, the hydrographic data showed a $\delta h_{\text {north }}$ value ( $>0.3 \mathrm{~m}$ ) considerably larger than that from the altimetry data. A close look at Figure $9 e$ reveals that this large $\delta h_{\text {north }}$ value is due to a small-scale surface height rise near the Japan coast along subtrack a123. This surface height rise was not captured by the Geosat measurement (which has a 17-day repeat cycle) possibly owing to the short duration of this warm water patch.

Since most hydrographic surveys shown in Figure 9 terminated around $30^{\circ} \mathrm{N}$, it is not possible to construct the time series of $\delta h_{\text {south }}$, which depends largely on the surface height values at the south edge of the southern recirculation gyre, from the hydrographic data. Though it is impossible to perform a direct comparison, indirect evidence for verifying the $\delta h_{\text {south }}$ time series (Figure $8 d$ ) will be shown in the next section in connection with the seasonal cycle of the Kuroshio.

\section{Seasonal Cycle of the Kuroshio and Its Possible Cause}

The seasonal variability of the Kuroshio south of Japan has been the subject of several previous studies. On the basis of quarterly geoelectrokinetograph (GEK) observations from 1955 to 1964, both Masuzawa [1965] and Taft [1972] found that the highest surface maximum velocity occurred in summer and the lowest maximum velocity occurred in fall. With more frequent GEK observations after 1960 (bimonthly), Nitani [1975] obtained a similar result, but was further able to determine that the maximum surface velocity occurred between the end of June and the middle of August (in the region of $135^{\circ}-139^{\circ} \mathrm{E}$ ). By analyzing quarterly hydrographic data from 1954 to 1984, Saiki [1985] also found a summer maximum in the eastward geostrophic transport of the upper $1000 \mathrm{~m}$ of the Kuroshio.

While consistent seasonal signals of the Kuroshio were obtained in these previous studies, the causes for the seasonal cycle and factors determining its phase are still unknown. As was pointed out in the introduction, low-frequency variations in the eastward transport of a boundary current can be attributed to both changes in the upstream inflow and in the boundary current recirculation gyres. The results of Figure 8, which captured the variations of the Kuroshio and its recirculation gyres, provide us with a unique data set for distinguishing these two possible causes. To focus on the seasonal changes, I first removed the linear trend in the time series of $\delta h_{\text {east }}, \delta h_{\text {south }}$, and $\delta h_{\text {net }}$ in Figure 8. (The time series of $\delta h_{\text {north }}$ is not considered here because the northern recirculation gyre is controlled mainly by the Kuroshio path variation, which has a time scale in the interannual frequency band.) The detrended data were then rearranged as a function of day of the calendar year. In Figure 11, solid lines show the two-month running mean averages of the detrended data and vertical bars denote their $95 \%$ confidence levels (assuming the detrended data are random and normally distributed).

A relatively well defined seasonal cycle appears in the fluctuations of $\delta h_{\text {east }}$ (Figure 11a). The maximum surface height difference or, equivalently, the maximum eastward surface transport of the Kuroshio occurs in July and Au- 

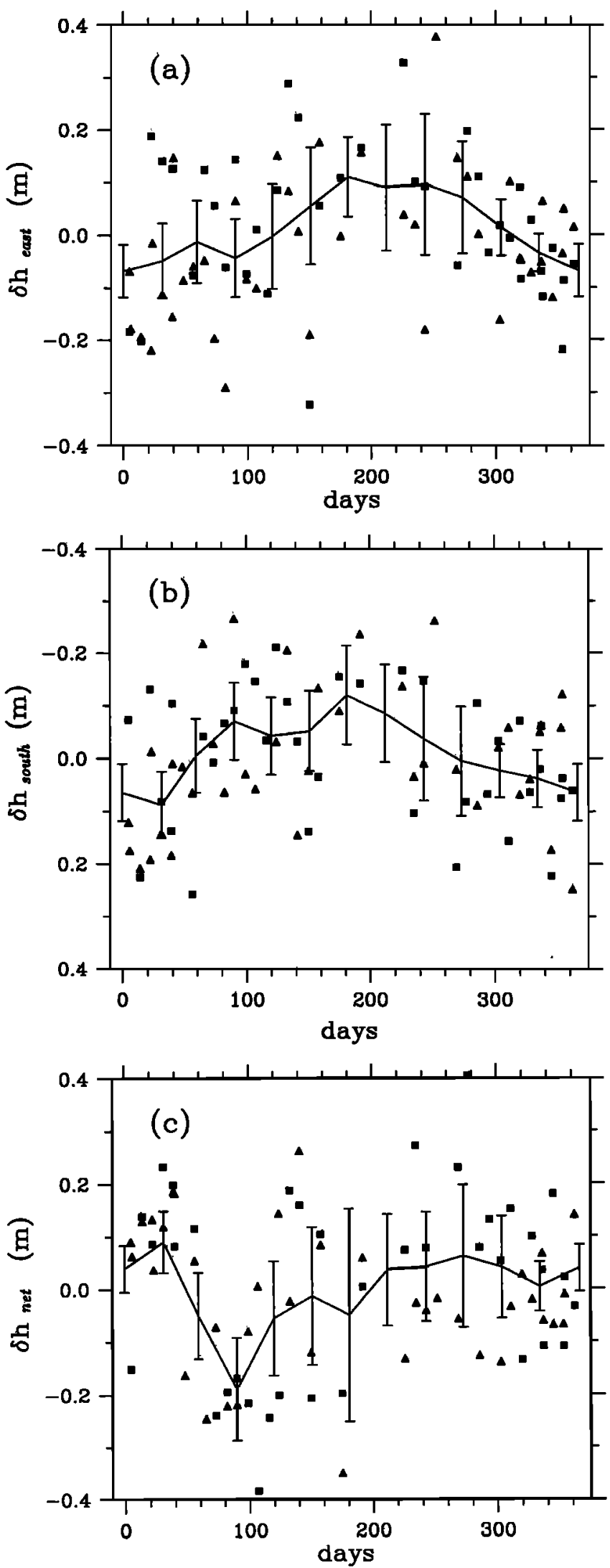

Fig. 11. Seasonal changes of the surface height differences acrose (a) the eastward flowing Kuroshio, (b) the southem recirculating flow, and (c) the entire Kuroshio system from $26^{\circ} \mathrm{N}$ to the Japanese cosit. Solid marks are based on time series shown in Figure 8, which are detrended and plotted here as a function of the day of a calendar year. Solid lines denote the 2-month running mean averages and vertical bars their $95 \%$ confidence levels. gust, a result in agreement with the previous studies using GEK and hydrographic data. Also well defined in seasonal cycle are fluctuations in $\delta h_{\text {south. }}$. Figure $11 b$ shows that the southern recirculation gyre intensifies rapidly in winter from January through March. The intensification slows down in the spring months, and after reaching the maximum in July, the magnitude of the recirculation gyre decreases steadily for the rest of the year. For both $\delta h_{\text {east }}$ and $\delta h_{\text {south, }}$ the amplitude of the seasonal change is about $0.1 \mathrm{~m}$. In contrast to these changes, the seasonal cycle in the net surface transport of the Kuroshio is not very well defined (Figure 11c). Significant $\delta h_{\text {net }}$ changes seem to be confined to the first 4 months of the year, namely, $\delta h_{\text {net }}$ has a maximum in Janaury and February, and is followed by a clear decrease in the subsequent 2 months. For the rest of the year, values of $\delta h_{\text {net }}$ are not significantly different from one month to the other.

The results of Figure 11 suggest that the seasonal cycle observed in the eastward transport of the Kuroshio is closely related to the seasonal change in the intensity of the southern recirculation gyre. The seasonal change of the southern recirculation gyre shown in Figure $11 b$ seems to support the "anticyclogenesis" model of Worthington [1976], who speculated that a cold continental air mass crossing the warm region of a boundary current causes large heat loss from the ocean to the atmosphere. The cooling of the ocean, preferentially south of the boundary current, deepens the thermocline and decreases the potential vorticity in the recirculation region, causing an intensification of the recirculation gyre. Lack of net heat flux observations in the Kuroshio region, unfortunately, prevented us from verifying this hypothesis. While the local atmospheric forcing is a plansible candidate for the seasonal cycle shown in Figure $11 b$, it will be left for future studies to clarify what determines the phase lag between the maximum surface cooling in December-January [Kurasawa et al., 1983] and the maximum $\delta h_{\text {south }}$ in the spring months. Despite its weak seasonal cycle, we note that changes in $\delta h_{\text {net }}$ are important in setting the phase of the maximum $\delta h_{\text {east. }}$. For example, the significant decrease in $\delta h_{\text {net }}$ in spring brings a gradual increase in $\delta h_{\text {east }}$ instead of an abrupt one as would have been the case if $\delta h_{\text {east }}$ were determinined solely by the southern recirculation gyre.

Although most oceanographic surveys south of Japan were confined in regions of the eastward flowing Kuroshio, an exception is along the $137^{\circ} \mathrm{E}$ meridian, where repeat hydrographic surveys extending from the coast of Japan to New Guinea have been perfomed by the Japan Meteorolog-

TABLE 1. Mean Geostrophic Transport of the Knroshio, the Kuroshio's Southern Recirculating Flow (KCC), and the Net Flow of the Kuroshio in January and July along $137^{\circ} \mathrm{E}$

\begin{tabular}{lrrc}
\hline & Kuroshio & KCC & Net Kuroshio \\
\hline January & 49.7 & -16.2 & 32.1 \\
July & 55.7 & -20.5 & 34.0 \\
\hline
\end{tabular}

Reference level is $1250 \mathrm{dbar}$. After Qiu and Joyce [1992]. Units are $10^{6} \mathrm{~m}^{3} \mathrm{~s}^{-1}$. 
ical Agency every January since 1967 and every July since 1972. By analyzing the past 22 years of data, Qiu and Joyce [1992] found that the difference in the eastward transport of the Kuroshio averaged in January and July can be attributed, up to $70 \%$, to the changes in intensity of the southern recirculation gyre (see Table 1). Their result from the hydrographic data supports the finding of the present study that the seasonal cycle in the eastward flowing Kuroshio is closely related to the seasonal changes in the southern recirculation gyre.

\section{Conclusions}

Recent advances in satellite altimetry observations have made it possible to study large-scale, low-frequency fluctuations of the western boundary currents using timedependent surface height field information. Owing to a lack of accurate geoid data, many previous studies have focused on the residual height difference across the boundary currents. Fluctuations in the surface height difference across a boundary current region can be caused by changes in both the inflow transport and the strength of the adjacent recirulating gyres. Separating these two signals is essential to the further understanding of the relationship between the wind and buoyancy forcing and the low-frequency fluctuations of the boundary currents. Such a separation, however, requires determination of the mean surface height profiles along satellite subtracks.

The present study proposed a method that estimates the mean surface height profile across an entire boundary current system including recirculation gyres. By extending the synthetic model of Kelly and Gille [1990], I assumed that the instantaneous surface velocity of the boundary current system consists of an eastward flowing jet and two possible westward recirculating flows, each of which is approximately Gaussian. Since the fluctuations of the eastward flowing jet dominates the residual height field, the mean surface height field associated with the eastward jet, $\left\langle h_{0}\right\rangle(y)$, was estimated first. Initial guesses for the synthetic height profiles of the recirculating flows were made based on the profiles of $h^{\prime}(y, t)+\left\langle h_{0}\right\rangle(y)$, and the shape of the mean recirculation gyres were improved by successively fitting the synthetic height data to the mean synthetic height plus the residual height data. The strengths of these gyres were determined by requiring the resultant mean surface height jump across the entire boundary current system to be a specified height difference value $\langle\delta h\rangle$.

To test this method, I applied it to the two Geosat subtracks in the Kuroshio region south of Japan. The $\langle\delta h\rangle$ value was determined from the long-term hydrographic surveys along the $137^{\circ} \mathrm{E}$ meridian. The mean surface height profiles thus estimated agreed well with the climatological mean of the surface dynamic height profile for both the Kuroshio and its recirculation regions. On the basis of the esimated mean surface height profiles, I separated the surface height signals into those associated with the eastward jet and those with the circulating flows. Comparisons between the time series of the eastward flowing Kuroshio and the northern recirculation from the altimetry data and those from the quarterly averaged hydrographic surveys also showed good agreement. Both of these comparisons confirmed the reliability of the method in determining mean surface height profiles along satellite repeat subtracks.

As was previously noted by studies based on GEK and hy- drographic observations, the present analysis based on the 2.3 years of the Geosat altimetry data showed that the eastward transport of the surface Kuroshio has a clear seasonal cycle (12-month period) with the maximum occurring in the months of July and August. Separating the surface height signals in the present study further helped to identify the possible cause for this seasonal cycle. It is found that the seasonal change in the eastward transport of the Kuroshio was closely related to the seasonal change in the intensity of the southern recirculation gyre. Changes in the net surface transport (which is plansibly related to the inflow from the upstream western boundary), on the other hand, seemed only to be important in delaying the time of the maximum transport by a few months. This result is consistent with a recent study by Qiu and Joyce [1992] based on repeat hydrographic surveys and it suggests that the local atmospheric forcing might be a more important factor in determining the seasonal change of a boundary current than the changes in the upstream inflow.

\section{APPENDIX}

The method of estimating the mean surface height profile along a satellite repeat track (section 3 ) requires that the mean surface height jump across the entire current system be known. For the Kuroshio south of Japan, this value, $\langle\delta h\rangle=0.76 \mathrm{~m}$, was determined from the long-term hydrographic surveys along $137^{\circ} \mathrm{E}$. It is highly possible that the $\langle\delta h\rangle$ value based on the climatology may differ from the true mean value of the surface height difference across the Kuroshio system for the Geosat ERM period. To estimate how the structure of the mean surface height depends on the a priori $\langle\delta h\rangle$ values, I calculated $\left\langle h_{r}\right\rangle(y)$ profiles for the subtrack a123 by using different $\langle\delta h\rangle$ values (Figure A1). Compared with the result of $\langle\delta h\rangle=0.76 \mathrm{~m}$, we note that the $\left\langle h_{r}\right\rangle(y)$ profiles using other $\langle\delta h\rangle$ values have essentially the same structure. This is not surprising because the detailed structure of the mean surface height is determined by the fitting of the residual height data, and $\langle\delta h\rangle$ only controls the strengths of the mean recirculation gyres.

Since it is the structure of the mean surface height profile that determines the separation of the signals, the time series of $\delta h_{\text {east }}, \delta h_{\text {north }}$, and $\delta h_{\text {south }}$ based on either of the $\left\langle h_{r}\right\rangle(y)$ profiles in Figure A1 remain the same as those in

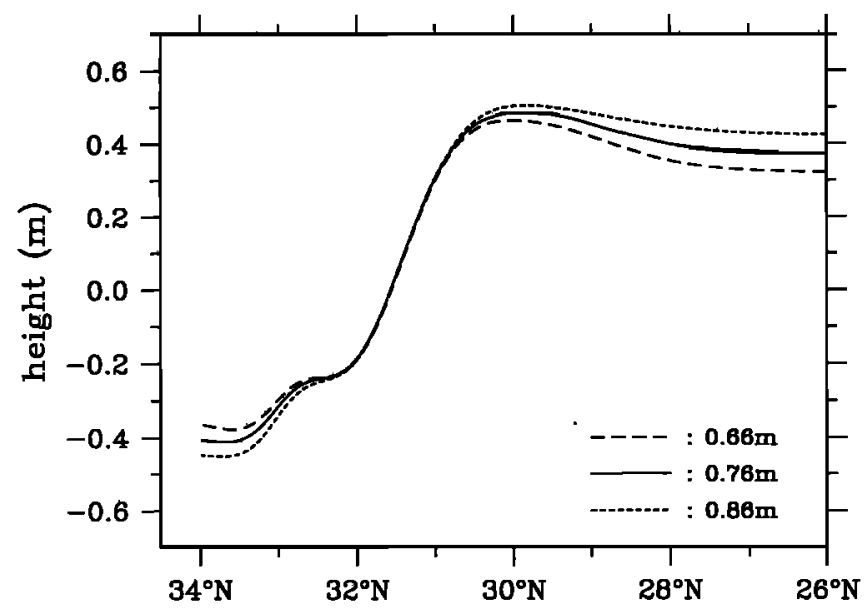

Fig. A1. Mean surface height profiles, $\left\langle h_{r}\right\rangle(y)$, estimated using different a priori $\langle\delta h\rangle$ values along subtrack a123. 
Figure 8, except for a constant offset in the respective $\delta h$ time series. Thus as long as a study focuses on the timedependent nature of a boundary current, the uncertainty in specifying the exact $\langle\delta h\rangle$ value in the proposed method is not critical.

Acknowledgments. This work was initiated through many discussions with Kathryn Kelly, whose extensive input is much appreciated. I am also grateful to Amy Bower, Sarah Gille, Terrence Joyce, and the reviewers for their criticisms and comments. Thanks are extended to Mike Caruso and Toshiko Turner for their technical support. This study was supported by the Office of Naval Research under contract NO0014-92-J-1656 and by the Woods Hole Oceanographic Institution. WHOI contribution 7939.

\section{REFERENCES}

Blaha, J., and R. Reed, Fluctuations of sea level in the western North Pacific and inferred flow of the Kuroshio, J. Phys. Oceanogr., 12, 669-678, 1982.

Fu, L.-L., J. Vaqquez, and M.E. Parke, Seasonal variability of the Gulf Stream from satellite altimetry, J. Geophys. Res., 92, 749-754, 1987.

Greatbatch, R.J., and J. Li, Barotropic variability in the presence of an ocean gyre, J. Mar. Res., 48, 37-53, 1990.

Hall, M.M., and H.L. Bryden, Profiling the Gulf Stream with a current meter mooring, Geophys. Res. Lett., 12, 203-206, 1985.

Hogg, N.G., A note on the deep circulation of the western North Atlantic: Its nature and causes, Deep Sea Res., 90, 945-961, 1983.

Hogg, N.G., R.P. Pickart, R.M. Hendry, and W.J. Smethie, Jr., The northern recirculation gyre of the Gulf Stream, Deep Sea Res., 99, 1139-1165, 1986.

Ishii, H., Y. Sekine, and Y. Toba, Hydrographic structure of the Kuroshio large meander-cold water mass region down to the deeper layers of the ocean, J. Oceanogr. Soc. Jpn., 39, 240$250,1983$.

Japan Oceanographic Data Center (JODC), Oceanographic Atlas of Japan-Chine Joint Research Program on the Kuroshio, 1-4, Tokyo, 1987-1990.

Joyce T.M., and W.J. Schmitz, Jr., Zonal velocity structure and transport in the Kuroshio Extension, J. Phys. Oceanogr., 18 1484-1494, 1988.

Joyce, T.M., C. Wunsch, and S.D. Pierce, Synoptic Gulf Stream velocity profiles through simultaneous inversion of hydrographic and acoustic Doppler data, J. Geophys. Res., 91, 7573$7585,1986$.

Joyce, T.M., K.A. Kelly, D.M. Schubert, and M.J. Caruso, Shipboard and altimetric studies of rapid Gulf Stream variability between Cape Cod and Bermuda, Deep Sea Res., 37, 879-910, 1990.

Kawabe, M., Sea level variations at the Izu Islands and typical stable paths of the Kuroshio, J. Oceanogr. Soc. Jpn., 41, 307326, 1985.

Kawabe, M., Variability of Kuroshio velocity assessed from the sea-level difference between Naze and Nishinoomote, $J$. Oceanogr. Soc. Jpn., 44, 293-304, 1988.

Kelly, K.A., The meandering Gulf Stream as seen by the Geosat altimeter: Surface transport, position, and velocity variance from $73^{\circ}$ to $46^{\circ} \mathrm{W}, J$. Geophys. Res., 96, 16,721-16,738, 1991 .

Kelly, K.A., and S.T. Gille, Gulf Stream surface transport and statistics at $69^{\circ} \mathrm{W}$ from the Geosat altimeter, J. Geophys. Res., $95,3149-3161,1990$.

Kelly, K.A., T.M. Joyce, D.M. Schubert, and M.J. Caruso, The mean sea surface height and geoid along the Geosat subtrack from Bermuda to Cape Cod, J. Geophys. Res., 96, 12,69912,709, 1991.

Kurasawa, Y., K. Hanawa, and Y. Toba, Heat balance of the surface layer of the sea at ocean weather station $T, J$. Oceanogr. Soc. Jpn., s9, 192-202, 1983.

Masuzawa, J., A note on the seasonal variation of the Kuroshio velocity, J. Oceanogr. Soc. Jpn., 21, 117-118, 1965.

Masuzawa, J., Water characteristics of the North Pacific central region, in Kuroshio-Its Physical A spects, edited by H. Stommel and K. Yoshida, Pp.95-128, University of Tokyo Press, Tokyo, 1972.

Niiler, P.P., and W. S. Richardson, Seasonal variability of the Florida Current, J. Mar. Res., 31, 144-167, 1973.

Nitani, H., Variation of the Kuroshio south of Japan, J. Oceanogr. Soc. Jpn., s1, 154-173, 1975.

Press, W.H., B.P. Flannery, S.A. Teukolsky, and W.T. Vetterling, Numerical Recipes, 818 pp., Cambridge University Press, New York, 1986.

Qiu, B., and T.M. Joyce, Interannual variability in the mid- and low-latitude western North Pacific, J. Phys. Oceanogr., 22, 1062-1079, 1992.

Qiu, B., K.A. Kelly, and T.M. Joyce, Mean flow and variability in the Kuroshio Extension from Geosat altimetry data, $J$. Geophys. Res., 96, 18,491-18,507, 1991.

Richardson, P.L., Average velocity and transport of the Gulf Stream near 55 $\mathrm{W}, J$. Mar. Res., 49, 83-111, 1985.

Saiki, M., On the transport of the Kuroshio, Mon. Mar. Sci., 17 267-273, 1985.

Schott, F.A., and R. Zantopp, Florida Current: Seasonal and interannual variability, Science, 227, 308-311, 1985.

Taft, B., Characteristics of the flow of the Kuroshio, in KuroshioIts Physical Aspects, edited by H. Stommel and K. Yoshida pp. 165-216, University of Tokyo Press, Tokyo, 1972.

Tai, C.-T., Estimating the surface transport of meandering oceanic jet streams from satellite altimetry: Surface transport estimates for the Gulf Stream and Kuroshio Extension, J. Phys. Oceanogr., 20, 860-879, 1990.

Uda, M., and K. Hasunuma, The eastward Subtropical Countercurrent in the western North Pacific Ocean, J. Oceanogr. Soc. $J p n ., 25,201-210,1969$.

Worthington, L.V., On the North Atlantic circulation, Johns Hopkins Oceanogr. Stud., 6, 110pp., 1976.

Wunsch, C., and E.M. Gaposchkin, On using satellite altimetry to determine the general circulation of the oceans with application to geoid improvement, Rev. Geophys., 18, 728-745, 1980.

Zlotnicki, V., Sea level differences across the Gulf Stream and Kuroshio Extension, J. Phys. Oceanogr., 21, 599-609, 1991.

B. Qiu, Woods Hole Oceanographic Institution, Woods Hole, MA 02543.

(Received January 31, 1992; revised July 17, 1992; accepted July 20, 1992.) 